16 a 18 de outubro de 2019 - Campinas | Brasil

\title{
Viabilidade e desempenho de água de reuso no amassamento do concreto
}

\author{
Isabella de Melo Conti*, Jorge Luiz da Paixão Filho.
}

\begin{abstract}
Resumo
A fabricação de concreto depende de uma grande quantidade de água. Usualmente utiliza-se água de abastecimento urbano cuja disbonibilidade vem diminuindo gradativamente e o reuso da água se faz necessário. O presente artigo analisa através de estudo experimental a viabilidade da água de reuso (AR) no amassamento do concreto, comparando o desempenho mecânico do concreto resultante ao feito com água potável (AP). Foi utilizado água de reuso proveniente da Estação de Tratamento de Esgoto (ETE) Capivari II e os parâmetros do concreto analisado foram: tempo de pega e resistência. Verificou-se que a água não apresenta contaminantes prejudiciais ao concreto e tem potencial para utilização na construção civil em substituição a água de abastecimento.
\end{abstract}

\section{Palavras-chave: \\ Construção civil, resistência à compressão, esgoto.}

\section{Introdução}

Todo ano são utilizados mais de um trilhão de litros de água potável pela indústria concreteira em todo o mundo, não sendo considerado a água da lavagem e cura do concreto (MEYER, 2004). Com a crise hídrica na cidade de São Paulo, muitas concreteiras e construtoras buscaram novas tecnologias como alternativa para a redução do consumo de água, como aditivos e maquinário moderno. Porém uma solução acessível e econômica seria a substituição da água potável por uma água de qualidade inferior na fabricação do concreto, como ocorre na Alemanha (RICKERT; GRUBE, 2016).

Segundo Petrucci (1998), a água que contém impurezas pode ser utilizada no amassamento do concreto sem apresentar, pelo menos aparentemente, efeitos danosos. Dessa forma, o objetivo desse trabalho foi analisar a água de reuso proveniente da Estação Produtora de Água de Reuso (EPAR) Capivari II, e a viabilidade de utilizá-la no amassamento do concreto, nos aspectos técnicos e mecânicos de desempenho.

\section{Resultados e Discussão}

A água foi analisada levando em conta os principais contaminantes prejudiciais ao concreto (Tabela 1).

Tabela 1. Resultados e requisitos da análise da água.

\begin{tabular}{|c|c|c|}
\hline Parâmetro & Requisito & Resultado \\
\hline Fosfato & $100 \mathrm{mg} / \mathrm{L}$ & $2,4 \mathrm{mg} / \mathrm{L}$ \\
\hline Nitrato & $500 \mathrm{mg} / \mathrm{L}$ & $12 \mathrm{mg} / \mathrm{L}$ \\
\hline Chumbo & $100 \mathrm{mg} / \mathrm{L}$ & $<0,01 \mathrm{mg} / \mathrm{L}$ \\
\hline Zinco & $100 \mathrm{mg} / \mathrm{L}$ & $0,03 \mathrm{mg} / \mathrm{L}$ \\
\hline Cloretos & $500 \mathrm{mg} / \mathrm{L}$ & $99 \mathrm{mg} / \mathrm{L}$ \\
\hline Sulfato & $2000 \mathrm{mg} / \mathrm{L}$ & $46 \mathrm{mg} / \mathrm{L}$ \\
\hline
\end{tabular}

Além dos contaminantes analisados, é importante verificar a presença de açúcar na água uma vez que o elemento se comporta como retardante do endurecimento do concreto. Dessa forma, o ensaio de tempo de pega foi realizado comparando a pasta de cimento feita com AR com a pasta de cimento com AP. A pasta de cimento feita com água de reuso apresentou desempenho similar à pasta feita com água potável (Tabela 2), portanto, é possível afirmar que a AR não contém traços de açúcar em quantidade prejudicial.

Tabela 2. Resultados do ensaio do tempo de pega.

\begin{tabular}{|c|c|c|}
\multirow{2}{*}{ Amostra } & \multicolumn{2}{|c|}{ Tempo decorrido } \\
\cline { 2 - 3 } & Início de pega & Fim de pega \\
\hline Água potável & $05: 40$ & $08: 07$ \\
\hline Água de reuso & $05: 20$ & $07: 50$ \\
\hline
\end{tabular}

No ensaio de resistência à compressão axial, foram comparados os resultados (Tabela 2) obtidos pelo concreto feito com AR com AP. O concreto de água de reuso apresentou desempenho inferior, porém muito próximo ao de água potável.

Tabela 2. Resultados dos ensaios de compressão axial.

\begin{tabular}{|c|c|c|}
\hline \multirow{2}{*}{ Amostra } & \multicolumn{2}{|c|}{ Resistência máx. à compressão } \\
\hline & Água potável & Água de reuso \\
\hline 1 & $22,80 \mathrm{MPa}$ & $22,30 \mathrm{MPa}$ \\
\hline 2 & $27,40 \mathrm{MPa}$ & $24,20 \mathrm{MPa}$ \\
\hline 3 & $26,50 \mathrm{MPa}$ & $24,80 \mathrm{MPa}$ \\
\hline 4 & $27,00 \mathrm{MPa}$ & $23,90 \mathrm{MPa}$ \\
\hline 5 & $27,50 \mathrm{MPa}$ & $22,00 \mathrm{MPa}$ \\
\hline Média & $26,24 \mathrm{MPa}\left(\mathrm{A}^{*}\right)$ & $23,44 \mathrm{MPa}\left(\mathrm{B}^{\star}\right)$ \\
\hline \multicolumn{3}{|c|}{ *Letras diferentes apresentam significância na análise estatística } \\
\hline \multicolumn{3}{|c|}{$\begin{array}{l}\text { método de cura utilizado na pesquisa (imersão na } \\
\text { água de reuso) pode ter provocado a diminuição da } \\
\text { resistência, considerando que a hidratação é o principal } \\
\text { responsável pela resistência do concreto (NEVILLE; } \\
\text { BROOKS, 2013). }\end{array}$} \\
\hline
\end{tabular}

\section{Conclusões}

De acordo com este trabalho conclui-se que

- A água de reuso não apresenta substâncias nocivas ao concreto, quando utilizada no seu preparo; o que foi comprovado pelo ensaio do tempo de pega;

- A resistência do concreto teve desempenho inferior quando comparado ao concreto de água potável, dessa forma seu uso estrutural não deve ser generalizado sem pesquisa mais aprofundada;

\section{Agradecimentos}

Universidade Presbiteriana Mackenzie e Sociedade de Abastecimento de Água e Saneamento (Sanasa) pelo apoio na realização desse trabalho.

MEYER, Christian. Sustainable Development and the Concrete Industry. CIB Bulletin. New York. 21 set. 2004. Disponível em <http://www.columbia.edu/cu/civileng/meyer/publications/publications/80\%2 0sustainable\%20development.pdf $>$. Acesso em: 17 maio 2019.

NEVILLE, A. M.; BROOKS, J. J.. Tecnologia do Concreto. 2. ed. Porto Alegre: Bookman, 2013. 448p.

PETRUCCI, Eladio G. R.. Concreto de Cimento Portland. 13. ed. São Paulo: Globo, 1998.

RICKERT, Jorg; GRUBE, Horst. Influence of recycled water from fresh concrete recycling systems on the properties of fresh and hardened concrete. VDZ, Concrete Technology Reports. Düsseldorf, Germany. 16 ago. 2016. 